\title{
ASSESSMENT OF SALINITY TOLERANCE IN AN INBRED POPULATION OF RICE (ORYZA SATIVA L) DERIVED FROM A JAPONICA X INDICA CROSS
}

\author{
Ranawake $\mathrm{AL}^{1} *$, Nakamura $\mathrm{C}^{2}$ \\ ${ }^{1}$ Faculty of Agriculture, University of Ruhuna, Mapalana, Kamburupitiya, Sri Lanka \\ ${ }^{2}$ Graduate School of Science and Technology, Kobe University, Japan 1-1 Rokkodai, Nada-ku, Kobe, 657- \\ 8501, Japan
}

Accepted : $06^{\text {th }}$ November 2011

\begin{abstract}
Development of methodologies for the characterization of parental rice cultivars under different abiotic stress conditions is important to exploit the genetic components of the relevant stress in populations using molecular tools such as QTL analysis. Japonica rice cultivar Hyogokithanishiki and Indica rice cultivar Hokuriku-142 (Hokuriku) were evaluated for salinity tolerance by EC solution method and MS (Murashige and Skoog) medium method. A plant nutrient solution was used to apply salinity stress for 12-day-old plants in EC solution method. NaCl was used to manipulate the salinity level in both methods. Green shoot length, dry matter weight and root length immediately after the stress and after recovering under normal conditions were measured in replicated experiments. Results showed that green shoot length is the best parameter for evaluation of salinity tolerance using EC solution method at $5 \mathrm{dS} /$ $m$. This method was therefore applied to an inbred line population $\left(163 \mathrm{~F}_{6}\right.$ lines $)$ derived from the two cultivars. The frequency distribution of green shoot length in the population showed a nearly normal distribution for surviving lines. Transgressive segregants were observed in both directions indicating the contribution of both parents for salinity tolerance in the population. The bio assay data can be utilized for QTL analysis upon construction of genetic map.
\end{abstract}

Key words: Bio Assay, Breeding, Electrical Conductivity, Salt Tolerance, Sodium Chloride, Tissue Culture

\section{INTRODUCTION}

Salinity affects rice production worldwide, particularly by reducing plant growth and potential yield. Rice is somewhat tolerant to salinity at germination stage (Abeysiriwardhana et al. 2004), very sensitive at early seedling stage and gains tolerance during vegetative growth. It becomes sensitive during pollen development stage but increasingly tolerant at maturity stage (Pearson et al. 1996). Expansion of salt affected lands resulting in the reduction of cultivable lands is a great challenge with the growing population in the world. Among various problems, irrigation is one of the problems that cause degradation of agricultural land leaving salts in soil after evapotranspiration. Soil salinity has been identified as caused by three different reasons; natural, clearing of native vegetation, and irrigation (Manneh et al. 2007). According to the classification of classes of soil salinity, low salinity; EC $2-4 \mathrm{dS} / \mathrm{m}$ can be caused by natural salinity and irrigation salinity. Species with low-moderate salt tolerance can be grown successfully under this salt stress. Moderate to high salt tolerant plant spe-

\footnotetext{
*Corresponding author : lankaranawake@agbio.ruh.ac.lk
}

cies are needed when the electrical conductivity falls between $4-8 \mathrm{dS} / \mathrm{m}$. This salinity is caused by irrigation. Under high-salinity conditions with EC exceeding $9 \mathrm{dS} / \mathrm{m}$, only halophytes can be grown (Maas and Hoffman 1977) According to Maas and Hoffman (1977) there exists a threshold salinity level that varies with species and with cultivar within species. Based on some published data, the salinity threshold for rice is around $3 \mathrm{dS} / \mathrm{m}$ at $25^{\circ} \mathrm{C}$ (Maas and Hoffman 1977).

Soil salinity constraints rice production and over $30 \%$ of the irrigated rice area in the world is affected by saline conditions due to irrational management and defective irrigation practices (Yeo and Flowers 1984). Current research (Maas and Grattan 1999; Hanson et. al. 1999) indicates that rice yields decrease $12 \%$ for every unit $(\mathrm{dS} / \mathrm{m})$ increase in above $3.0 \mathrm{dS} / \mathrm{m}$. The growth under saline conditions depends on the reducing ability of sodium and chloride uptake while maintaining potassium uptake in to the plant (Koyama et al. 2001). The development of appropriate techniques for manage- 


\section{RANAWAKE AL ET AL: SALINITY TOLERENCE IN INBRED LINE POPULATION}

ment of salinity is critical for optimizing rice performance under saline or potentially saline conditions. Mass and Grattan (1999) reported that yields cannot be improved under saltstressed conditions by increasing the seeding rate. They found that high field-water levels are more growth limiting than shallow water levels. Therefore, the solution for rice growers who are facing salinity problems is, irrigation management strategies that maintain low levels of salinity stress while minimizing high field water levels (Grattan and Grieve 1999) Various methods such as soil reclamation, excessive irrigation, and soil drainage are used to minimize soil salinity; they are always laborious and expensive. Therefore other strategies such as varietal improvement also need to be considered for constant and profitable rice production.

There are several factors influencing salt tolerance in plants. The most important among these are species, temperature, salt composition, growth stage of plant, salinity level, environmental variables, soil fertility and cultivar (Fageria 1985). Physiological characterization of rice cultivars showed that tolerant genotypes maintained a much lower shoot $\mathrm{Na}+$ concentration relative to sensitive genotypes under salinity stress (Walia et al. 2007).

Though attempts have been made to change the salt tolerance of important crops over many years, the success achieved in producing salt tolerant varieties however has been very limited (Flowers et al. 2000). Most of the processes found to be important in plant resistance or tolerance of salinity exhibit quantitative inheritance, hence they show continuous variation and a high degree of environmental interactions (Koyama et al. 2001). Evolutionary adaptation to salinity involves complicated physiological and developmental processes (Flowers and Dalmond, 1992) making breeding for salt tolerance a difficult challenge.

Selection of salinity tolerant parental lines considering physiological criteria and pyramiding those traits resulted in the release of two culti- vars with enhanced resistance to salt (IRRI, 1997). The genetic parameters of rice salt tolerance have been confirmed for a few morphological and physiological traits such as shoot length, root length, shoot fresh weight, shoot dry weight and shoot $\mathrm{Na}+/ \mathrm{K}+$ concentration in saline soils (Yeo and Flowers, 1984; Pearson et al., 1996).

Salinity screening studies vary quite drastically at both spatial and temporal levels depending on objectives (Grattan and Grieve, 1999). Some studies examine response at the molecular level while others examine response at the field or regional level ( $\mathrm{Gu}$ et al., 2005; Kamoshita et al., 2001; Zhang et al., 2005). The entire duration of some experiments may be minutes, as in short-term uptake studies using isotopes, while others may span seasons (Grattan and Grieve, 1999).

Introgression of Japonica rice cultivars with Indica rice cultivars to overcome the narrow gene pool is well practiced in broad areas of development of stress tolerant rice cultivars. Because of independent domestication events for Indica and Japonica subspecies for centuries of farmer selection, certain groups of alleles have been brought together in what are known to be traditional varieties. For example, tropical Japonica rice varieties can be characterized as having thick, dark green leaves, negative phenol reaction, thick roots, and limited tillering (Saxena, et al. 2002). Further, Indica rice cultivars named Pokkali and NonaBokara are well-known to be salt tolerant with high heritability values (Gregorio and Senadhira 1993) but it is considered that salt tolerance is co-inherited with other undesirable agronomical characters (Heu and Koh 1991).

In the present study we tested salinity tolerance of 163 inbred lines of $F_{6}$ generation derived from a cross between Indica and Japonica parents. The Indica parental cultivar, Hokurikuriku-142 (Hokuriku) and Japonica parental cultivar, Hyogokithanishiki were genetically divergent types, which would provide enough 
segregation for both molecular marker alleles and agronomically important genes. None of the parents were reported to be salinity tolerant previously. The objective of this study was to investigate the effectiveness of new breeding materials for rice salt tolerance through genetic recombination between Indica and Japonica rice.

Currently available screening methodologies for salinity have their own limitations. In the present study two methods and several parameters were used to evaluate salinity tolerance in two parental rice cultivars by laboratory experiments and the methodology was confirmed by applying to the inbred line population derived from them.

\section{MATERIALS AND METHODS}

Genotypes used in the study: A recombinant inbred line (RIL) population ( $\mathrm{F}_{6}$ generation) comprising of 163 lines derived from a cross between cold tolerant Japonica rice cultivar, Hyogokithanishiki, and a cold susceptible Indica rice cultivar, Hokuriku was used. Hokuriku was bred from a cross between a Korean cultivar, Milyang 21 and an IRRI line IR-2061214-31 at the Hokuriku Agricultural Experimental Station, Japan. Inbred line populations were advanced according to the single seed descent method and were selfed at each generation.

Evaluation of parental cultivars for salinity tolerance: Salinity tolerant levels of the two parental cultivars were evaluated by growing them in solutions with different levels of electrical conductivity (EC) and also by growing plants on MS media (Murashige and Skoog 1962) with different concentrations of $\mathrm{NaCl}$ under aseptic conditions.

Growing plants in different levels of EC solutions: Seeds of the parental cultivars were surface sterilized, germinated and grown in 1X10 ${ }^{-6}$ Hyponex (N:P:K: 6:10:5, Toyoba, Japan) solution. The experiment was repeated three times in plastic basins, which had upper vessels to keep the plants upright and holes in the bottom of the upper vessels to get $1 \mathrm{ppm}$ Hyponex solution from 2 liter capacity lower basin. Hyponex solution was refreshed every other day for 12 days.

Electrical conductivity calibration curve for $\mathrm{NaCl}$ was prepared first using the same source of water and $\mathrm{NaCl}$ used in the experiment. Then Hyponex solutions were prepared with a series of EC values from EC 1 to EC 14 by adding $\mathrm{NaCl}$. Twelve-day-old plants were subjected to salinity stress in EC solutions for 8 days. A control experiment was carried out in $1 \mathrm{X} 10^{-6}$ Hyponex solution. Three replicates were arranged for each EC level and each replicate contained ten plants. During the stress period, Hyponex solution was renewed every other day. After salinity stress, plants were allowed to recover in $1 \times 10^{-6}$ Hyponex solution for 5 days. On the 5 th day of the recovery period, length of green shoot, length of the longest root, dry matter weight of roots and shoots were recorded.

Growing plants on MS media with different concentrations of $\mathrm{NaCl}$ : Seeds of parental cultivars were surface sterilized and germinated under aseptic conditions. Germinated seeds were planted in MS basal medium and maintained for 12 days. MS media were prepared with a series of $\mathrm{NaCl}$ concentrations from 25 $\mathrm{mmol} / \mathrm{l}$ to $400 \mathrm{mmol} / \mathrm{l}$, creating 10 different levels of salinity stresses for the plants. Twelve -day-old seedlings were transferred to salinized MS media and maintained for 8 days at $26 \pm 2^{\circ} \mathrm{C}$ with a 12-h photoperiod (160 $170 \mathrm{mmol} \mathrm{m}-2 \mathrm{~s}^{-1}$ ) from daylight fluorescent tubes (Philips TLD 38/54). Ten replicates for each treatment were arranged with 3 plants for each replicate. Then plants were given a 6-day recovery period in tap water (Fig.1). Green shoot length immediately after salinity stress, root length of plant immediately after salinity stress, green shoot length of plant after recovery period, root length of plant after recovery period and dry matter weight of plant after recovery period were collected for comparison of level of salinity tolerance in two parental cultivars, Hyogokithanishiki and Hokuriku.

Evaluation of salinity tolerance of inbred lines derived from Hyogokithanishiki and Hokuriku :Sixty seedlings of each inbred line were planted according to a complete random- 
ized design and the experiment was repeated three times in plastic basins, which had upper vessels to keep the plants upright and holes in the bottom of the upper vessels to get $1 \times 10^{-6}$
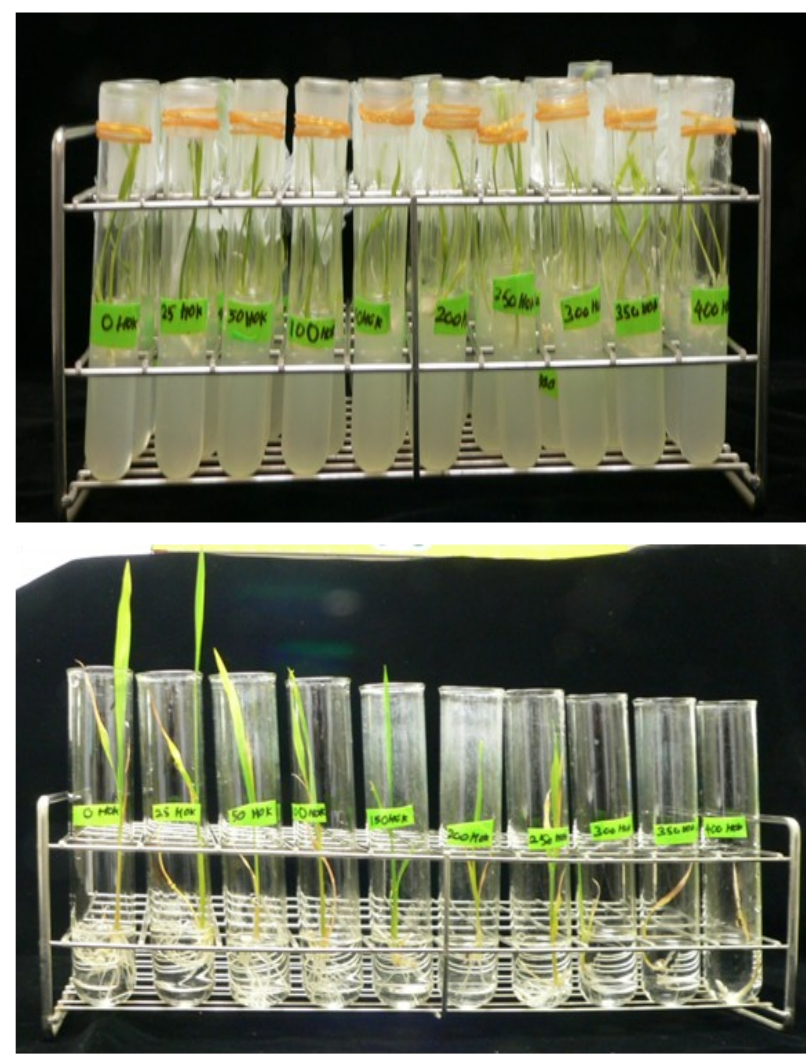

Figure 1: Figure 1 Evaluation of parental cultivars for salinity tolerance on MS medium with different concentrations of $\mathrm{NaCl}$. A: Seedlings under stress conditions on MS medium, B: Seedlings at the end of the 5 day recovery period in water. From left to right, Hyponex solution $\left(1 \times 10^{-6}\right)$ supplemented with 0,25 , $50,100,150,200,250,300,350,400 \mathrm{mmol} / \mathrm{l} \mathrm{NaCl}$.

Hyponex solution from 2liter capacity lower basin. Salinity stress $(5 \mathrm{dS} / \mathrm{m})$ was applied over a 8-day period for 12 day old plants. After salinity stress, plants were allowed to recover in $1 \times 10^{-6}$ Hyponex solution for 5 days. On the 5 th day of the recovery period, length of green shoot, length of the longest root, dry matter weight of roots and shoots were recorded.

\section{RESULTS AND DISCUSSION}

EC solution method: Hyogokithanishiki and Hokuriku recorded similar green shoot length up to EC $2 \mathrm{dS} / \mathrm{m}$ (Fig.2). At salinity levels greater than EC $3 \mathrm{dS} / \mathrm{m}$ Hyogokithanishiki recorded significantly higher green shoot length. This difference in the two cultivars was most evident between EC $5 \mathrm{dS} / \mathrm{m}$ and $9 \mathrm{dS} / \mathrm{m}$ (Fig. 2).

At different EC solutions, up to EC level 2 dS/ $\mathrm{m}$, green shoot length of both Hokuriku and Hyogokithanishiki was almost the same but from EC level $3 \mathrm{dS} / \mathrm{m}$ Hokuriku plant height was decreased while Hyogokithanishiki could maintain higher green shoot length (Fig.2). Root length of both Hyogokithanishiki and Hokuriku decreased from $2 \mathrm{dS} / \mathrm{m}$ to $14 \mathrm{dS} / \mathrm{m}$

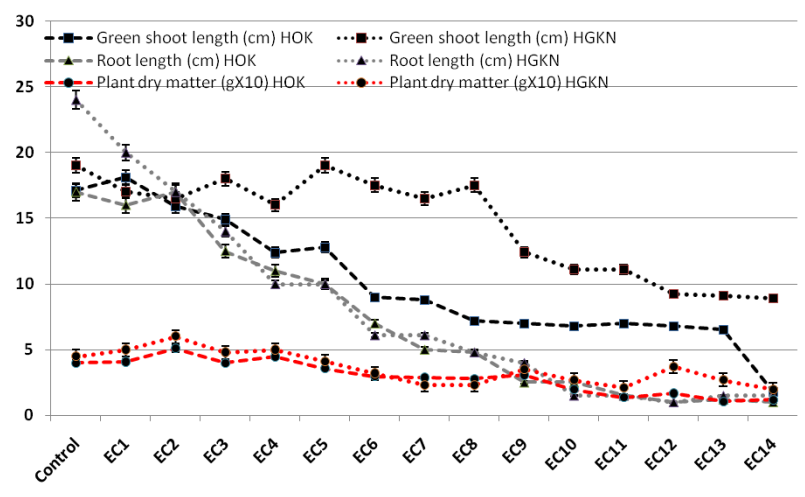

Figure 2 ; Green shoot length (cm); root length (cm); plant dry matter weight (g) of seedlings that survived at the $10^{\text {th }}$ day of recovery after a 8-day salinity stress from $1 \mathrm{dS} / \mathrm{m}$ to $14 \mathrm{dS} / \mathrm{m}$ (n=20, denoted EC1 - EC14). Bars indicate standard errors. HGKN: Hyogokithanishiki, HOK: Hokuriku.

(Fig.2). Both cultivars maintained relatively high plant dry matter weight up to EC level 4 $\mathrm{dS} / \mathrm{m}$. Plant dry matter weight of Hokuriku was drastically reduced from $4 \mathrm{dS} / \mathrm{m}$, whereas in Hyogokithanishiki, a significant dry matter reduction was observed from EC level $5 \mathrm{dS} / \mathrm{m}$. From EC level $6 \mathrm{dS} / \mathrm{m}$, Hyogokithanishiki dry matter production was also decreased and from EC level $9 \mathrm{dS} / \mathrm{m}$ onward both cultivars showed low level of dry matter production (Fig. 1). The highest difference between two rice cultivars in dry matter production was recorded at $12 \mathrm{dS} / \mathrm{m}$ (Fig. 2). Gregorio and Senadhira (1993) also selected $12 \mathrm{dS} / \mathrm{m}$ EC level for salinity tolerance studies in rice for 14 day old seedlings after manipulating EC level by adding a 16:1 mixture of $\mathrm{NaCl}$ and $\mathrm{CaCI}_{2}$ to the nutrient solution which is in agreement with the threshold level achieved in the present study.

Effect of salinity on rice and tolerance levels in rice cultivars have been studied in hydroponic culture systems with $60 \mathrm{~mol} / \mathrm{m}^{3} \mathrm{NaCl}$ (Gu et al. 2000). They ranked cultivars for salt injury, $\mathrm{Na}+$ content in shoot, ratio of shoot fresh 
weight and dry matter weight at seedling stage and different agronomic traits in control and salt-treated plants at mature stage $(\mathrm{Gu}$ et al. 2000), The physiological changes in salt stressed rice are directly impaired on overall growth such as shoot height, fresh weight and dry weight (Aslam et al. 1993; Chowdhury et al. 1995; Sohn et al. 2005; Khan and Panda, 2008).

MS medium method: Hyogokithanishiki recorded significantly higher green shoot length and root length after recovery period in MS basal medium compared to Hokuriku (Fig. 3). When the green shoot length was measured immediately after the stress treatment, Hyogokithanishiki recorded higher green shoot length up to $100 \mathrm{mmol} / \mathrm{l} \mathrm{NaCl}$ stress, but when the salinity stress was increased further, Hokuriku recorded higher green shoot length than Hyogokithanishiki (Fig. 3). Thach and Pant (1999) also reported a significant decrease in relative growth based on fresh weight when 14day old seedlings were shifted into test tubes containing the nutrient solutions with different $\mathrm{NaCl}$ concentrations. The same has been reported by Cha-um et al. (2009) where the less growth reduction percentage in $342 \mathrm{mmol}$ $\mathrm{NaCl}$ stressed was observed in salinity tolerant KDML105 compared to salinity susceptible HJ seedlings. Wani and Gosal (2011) reported the existence of the same phenomena in salinity tolerant gene transformation work

In the experiment carried out to evaluate level of salt tolerance of two rice cultivars on MS medium, immediately after $\mathrm{NaCl}$ stress, Hokuriku cultivar showed significantly higher green shoot length than Hyogokithanishi at higher $\mathrm{NaCl}$ levels $(>150 \mathrm{mmol} / \mathrm{l})$, but after the recovery period in water, Hyogokithanishiki showed significantly higher green shoot length (Fig. 3). This could not be seen in root length. At both stages, immediately after salt stress and after recovery, Hokuriku reported shorter roots than Hyogokithanishiki (Fig. 4). This could be due to varietal $\mathrm{X}$ tissue culture medium interaction. In the control treatment, Hokuriku in MS medium recorded higher dry matter weight than Hyogokithanishiki (data not shown). Therefore, the tissue culture-based approach we tested is not sufficiently reliable to evaluate rice cultivars for salinity stress tolerance due to varietal $\mathrm{X}$ medium interactions give false results to-

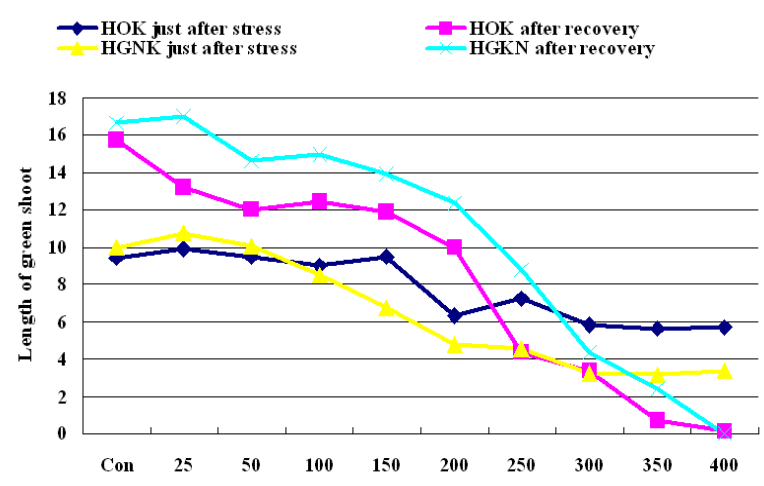

Figure 3. Green shoot length of seedlings that survived after salinity stress imposed using $\mathrm{NaCl}$ in $\mathrm{MS}$ medium. HGKN: Hyogokithanishiki, HOK: Hokuriku.

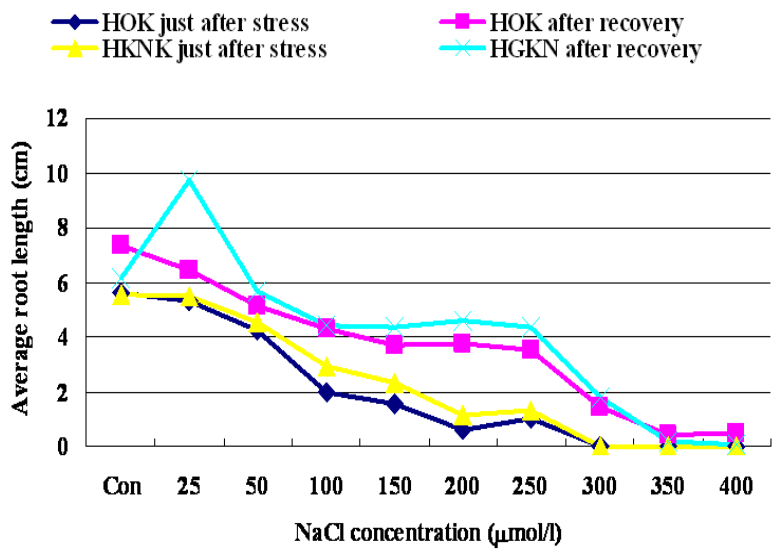

Figure 4. Root length of seedlings that survived the salinity stress at different $\mathrm{NaCl}$ concentrations in $\mathrm{MS}$ medium. HGKN: Hyogokithanishiki, HOK: Hokuriku.

wards stress tolerance. In the study carried out by Vajrabhaya et al. (1989), the salinity tolerant selection was done at 2- 4 week old callus, in the callus induction medium with $2 \% \mathrm{NaCl}$ concentration. They had not reported a variety $\mathrm{X}$ medium interaction. However, rice variety $\mathrm{X}$ medium interactions have been reported in many other studies (Rahim et al. 1991; Nguyen and Zapata 1993; Islam et al. 2005).

According to the $A N O V A$ results, none of the parameters studied using MS medium recorded significant differences between the two rice cultivars (Table 1). The reason why it did not show a significant difference between the parental cultivars for root length under different EC stresses would be that 8 day period in $\mathrm{NaCl}$ solutions was not enough to show that much difference. In addition, the initial root system was not damaged before the application of salinity stress to evaluate the length of the long- 


\section{RANAWAKE AL ET AL: SALINITY TOLERENCE IN INBRED LINE POPULATION}

est root. Nevertheless, solution culture studies are beneficial since they have advanced our understanding of crop salt-tolerance and have provided insight into physiological mechanisms responsible for nutrient uptake and disTable 1: ANOVA results of all parameters collected from salinity stress treatment

\begin{tabular}{|c|c|c|}
\hline Method & Parameter & $\mathrm{P}$ value \\
\hline \multirow{4}{*}{$\begin{array}{l}\text { EC solution } \\
\text { method }\end{array}$} & Green shoot length & 0.006645 \\
\hline & Root length & 0.308319 \\
\hline & Plant fresh weight & 0.03743 \\
\hline & Plant dry matter weight & 0.061928 \\
\hline \multirow{5}{*}{$\begin{array}{l}\text { MS medium } \\
\text { method }\end{array}$} & $\begin{array}{l}\text { Shoot length immediately after } \\
\text { stress }\end{array}$ & 0.271575 \\
\hline & Shoot length after recovery & 0.4338 \\
\hline & Root length just after stress & 0.761256 \\
\hline & Root length after recovery & 0.6909 \\
\hline & Plant dry matter weight & 0.106916 \\
\hline
\end{tabular}

crimination (Gratten and Grieve 1999). .Further in solution cultures, concentrations of salts and nutrients are easily controlled over the course of an experiment. Plant responses and interactions observed in artificial media may not necessarily occur as they would under natural conditions. However, solution culture studies are beneficial since they have advanced our understanding of crop salt-tolerance.

Considering literature on solution culture and our own results, salinity level corresponding to EC $5 \mathrm{dS} / \mathrm{m}$ was decided as the most suitable EC level to apply for the evaluation of inbred line population and green shoot length was used in the bioassay. Under $5 \mathrm{dS} / \mathrm{m}$ salinity stress for 8 days, 64 out of 163 inbred lines (39.2\%) dried completely and 21 inbred lines $(12.9 \%)$ recorded longer green shoot length than salinity tolerant Hyugokithanishiki (Fig. 5). Salinity susceptible parent Hokuriku did not dry completely and scored $12 \mathrm{~cm}$ green shoot length (Fig. 6). The most salinity tolerant lines scored $35 \mathrm{~cm}$ green shoot length compared to $18 \mathrm{~cm}$ in the salinity tolerant parent. Transgressive segregation of the population in both directions was observed indicating that the salinity tolerance of this population is controlled by both parental alleles. Each pair of replicate in salinity tolerant screening of inbred line population showed positive correlations bringing evidence on the consistency of bio assay data.

\section{CONCLUSION}

Green shoot length of the salinity stressed Hyogokithanishiki plants showed a significant

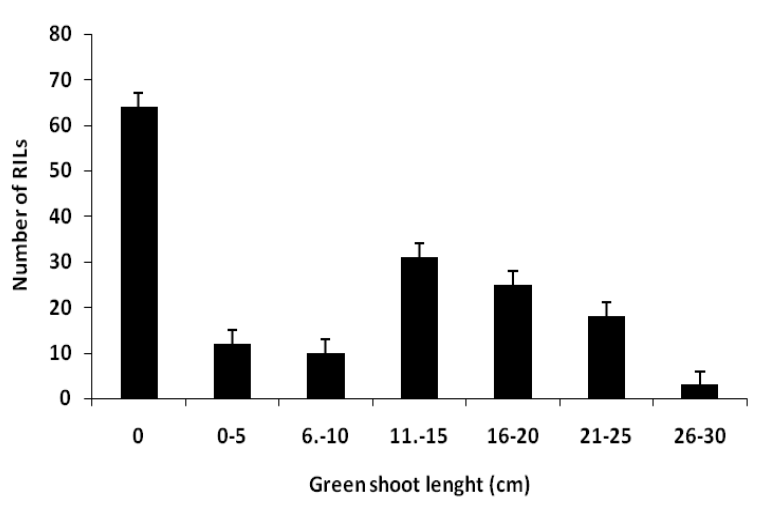

Figure 5 Frequency distribution of the RILs after salinity stress at $5 \mathrm{dS} / \mathrm{m}$. Data was taken on the 10th day of the recovery period after 8-day salinity stress. The experiment was repeated three times.

difference from Hokuriku in EC solution method. EC level $5 \mathrm{dS} / \mathrm{m}$ recorded the greatest difference among the parent cultivars, and selecting this level of salinity to screen the inbred line population derived from them enabled us to differentiate the lines according to their tolerance level. Frequency distribution of inbred line population shows that the method applied to evaluate the salinity tolerance is reliable and practically applicable to screen large populations. The results of the bio assay can be directly used for salinity tolerant QTL analysis in future.

\section{ACKNOLEDGMENT}

The first author wishes to acknowledge Monbukagakusho (Ministry of Education, Culture, Sports, Science and Technology, Government of Japan) for providing financial support for postgraduate studies in Japan, Prof. Shinya Yoshida, Hyogo Institute of Agriculture, Forestry and Fishery, Japan for providing plant materials, Prof. Naoki Mori and Prof. T. Ishii, Kobe University Japan for technical support, Prof. Ranjith Pathirana for valuable criticism, editing, and careful thorough reading of the manuscript.

\section{REFERENCES}

Abeysiriwardhana DSZ, 2004 A simple screening techniques for salinity tolerance in rice: Germination rate under stress. IRRN 29 (2):78-79

Aslam M, Qureshi RH and Ahmed N 1993 A rapid screening technique for salt tolerance in rice (Oryza sativa L.). Plant Soil 150:99-107

Cha-um S, Trakulyingcharoen T, Smitamana P, Kirdmanee C 2009 Salt tolerance in two rice 


\section{Jropical Agrieultural Research \& Extension 15(3): 2012}

cultivars differing salt tolerant abilities in responses to iso-osmotic stress. Australian Journal of Crop Science 3(4):221-230

Chowdhury MAM, Moseki B, Bowling DJF 1995 A method for screening rice plants for salt tolerance. Plant Soil 171:317-322

Fageria NK 1985 Salt tolerance of rice cultivars. Plant and Soil. 88: 237-243

Flowers TJ, Dalmond D 1992. Protein synthesis in halophytes - the influence of potassium, sodium and magnesium in in vitro. Plant and Soill 46:153-161

Flowers TJ, Koyama ML, Flowers SA, Sudhakar C, Singh KP and Yeo AR 2000 QTL: their place in engineering tolerance of rice to salinity. J. Exp. Bot. 51: 99-106

Grattan SR and Grieve CM 1999 Salinity mineral nutrient relations in horticultural crops. Scientia Horticulturae 78:127-157

Gregorio GB and Senadhira D 1993 Genetic analysis of salinity tolerance in rice (Oryza sativa L.). Theor Appl Genet 86: 333-338

Gu X-Y, Mei M-T, Yan X-1, Zheng S-1 and Lu YG, 2000 Preliminary detection of quantitative trait loci for salt tolerance in rice. 14: 65-70

Hanson B, Grattan SR and Fulton A 1999 Agricultural salinity and drainage, UC DANR Pub 3375:160 p

Heu MH and Koh HJ 1991 Newly bred salt tolerance lines in rice. Kor. J. Breed 23:59 63

IRRI 1997 Rice varieties boost yield and improve saline soils. In: Partners Making a Difference. Eds. C Dedolph, G Hettel. International Rice Research Iinstitute, Manila. 37

Islam M, Ahmed M and Mahaldar D 2005 In vitro callus induction and plant regeneration in seed explants of rice (Oryza Sativa L.). Research Journal of Agriculture and Biological Sciences 1 (1):72-75

Kamoshita A, Zhang J, Siopongco J, Sarkarung S, Nguyen HT and Wade L 2001 Effects of phenotyping environment on identification of QTL for rice root morphology under anaerobic conditions. Crop Science, 42: 255-265

Khan MA and Abdullah Z 2000 Salinity-sodicity induced changes in reproductive physiology of rice (Oryza sativa) under dense soil conditions. Environ Exp Bot 49:145-157

Koyama M, Levesley A, Koebner R, Flowers T and Yeo A 2001 Quantitative trait loci for component physiological traits determining salt tolerance in rice. Plant Physiology 125: 406-422

Maas EV and Grattan SR 1999 Crop yields as affected by salinity. In: Skaggs RW, van Schilfgaarde J (eds.). Agricultural Drainage. Agron Monogr 38. ASA, CSSA, SSA, Madison WI. Pp. 55-108

Maas EV and Hoffman GJ 1977 Crop salt tolerance -current assessment. J. Irrig. Drainage Div. Asce. 103: 115-134
Manneh B, Satm P, Struik PC, Bruse-Oliver S and Eeuwik FAV 2007 QTL-based analysis of genotype by environment interaction for grain yield of rice in stress and non-stress environments. Euphytica 156: 213-226

Murashige T and Skoog F. 1962 A revised medium for rapid growth and bioassays with tobacco tissue cultures. Physiologia Plantarum 5 473-497

Nguyen MD and Zapata FJ 1993 FJ Effect of interaction between genotype and culture medium on callus induction and plant regeneration of anther culture of Vietnamese Indica rice. IRRN 18(3): 10-11

Pearson GA, Ayers AD and Eberhard DL 1996 Relative salt tolerance of rice during germination and early seedling development. Soil Science. 102, pp:151- 156

Rahim MA, Hakim L and Miah AJ 1991 Induction of callus and plant regeneration. Plant Tissue Culture, 1(1):27-30

Saxena, NP and O'Toole JC, (eds.) 2002 Field screening for drought tolerance in crop plants with emphasis on rice: Proceedings of an International Workshop on Field Screening for Drought Tolerance in Rice, 11-14 Dec 2000, ICRISAT, Patancheru, India. Patancheru, Andhra Pradesh, India, and the Rockefeller Foundation, New York, USA.

Sohn YG, Lee BH, Kang KY, Lee JJ 2005 Effects of $\mathrm{NaCl}$ stress on germination, antioxidant responses, and proline content in two rice cultivars. J Plant Biol 48:201-208

Thach JN, Pant RC 1999 In vitro study on salt tolerance in rice. Omonrice 7:80-88

Vajrabhaya M, Thanapaisal $\mathrm{T}$ and Vajrabhaya $\mathrm{T}$ 1989 Development of salt tolerant lines of KDML and LPT rice cultivars through tissue cultures. Plant Cell Rept., 8: 411-414

Walia $\mathrm{H}$, Wilson $\mathrm{C}$, Zeng L, Ismail $\mathrm{A}$, Condamine $P$ and Close T 2007 Genome-wide transcriptional analysis of salinity stressed Japonica and Indica rice genotypes during panicle initiation stage. Plant Molecular Biology 63:609-623

Wani SH and Gosal SS 2011 Introduction of OsglyII gene into Indica rice through particle bombardment for increased salinity tolerance. Biologia Plantarum 55 (3): 536-540

Yeo AR and Flowers TJ 1984 Mechanism of salinity resistance in rice and their role as physiological criteria in plant breeding In: salinity tolerance in plants-Strategies for crop improvement. (eds.) Staples RC and Toenniessen GH WileyInter science Publication, New York, 151-170

Zhang ZH, Su LLW, Chen W, and Zhang, YG 2005 A major QTL conferring cold tolerance at the early seedling stage using recombinant inbred lines of rice (Oryza sativa L.) Plant Sci. 168: 527-534 